Supporting information for

\title{
Retro-Techno-Economic Analysis (RTEA): using (bio)process systems engineering tools to attain process target values
}

Felipe F Furlan ${ }^{a}$, Caliane B B Costa ${ }^{b}$, Argimiro R Secchi ${ }^{c}$, John M Woodley ${ }^{d}$, Roberto C Giordano ${ }^{a *}$

${ }^{a}$ Chemical Engineering Graduate Program, Universidade Federal de São Carlos (UFSCar), Rodovia Washington Luís (SP-310), km 235, São Carlos - SP - Brazil, CEP: 13565-905

${ }^{b}$ Chemical Engineering Department, Universidade Estadual de Maringá (UEM), Avenida Colombo, 5790, Maringá, Paraná, Brazil, CEP: 87020-900

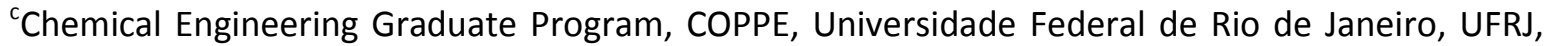
Cidade Univesitária, Rio de Janeiro, RJ, Brazil, CEP: 21941-972

${ }^{\mathrm{d} D e p a r t m e n t}$ of Chemical and Biochemical Engineering, Technical University of Denmark, DK-2800 Kgs. Lyngby, Denmark

*E-mail of corresponding author: roberto@ufscar.br 


\section{Mathematical modeling}

All the operations in the succinic acid production were modeled as short-cut models, with mass and energy balances and design correlations. The basic stream, used to connect the different pieces of equipment, is constituted by the total mass flow $(F)$, component mass fractions $(z)$ and temperature $(T)$. The modeling language of EMSO implements aspects of object-oriented languages. Therefore, the temperature of the inlet stream of unit1, for example, is described as unit1.inlet.T. This language will be used in the models description below.

\section{Models description}

\subsection{Mixer}

The mixer was modeled with two inlets and one outlet stream. The global mass balance and component mass balance are shown in equations 1 and 2. As a simplification, the energy balance was not performed in this model, with the outlet temperature being specified.

Inlet $1 . F+$ Inlet $2 . F=$ Outlet. $F$

Inlet1. $F \times$ Inlet $1 . z[i]+$ Inlet $2 . F \times$ Inlet $2 . z[i]=$ Outlet. $F \times$ Outlet. $z[i]$

\subsection{Splitter}

The splitter was modeled with one inlet and two outlets. A split fraction $(f)$ is defined, which represents the mass flow of the inlet that is diverted to the first outlet (eq. 3). The global mass balance is also calculated (eq. 4) and both outlets composition is supposed to be equal to the inlet one (eq. 5). Finally, thermal equilibrium is supposed between all streams (eq. 6). 
Outlet1.F $=f \times$ Inlet. $F$

Inlet. $F=$ Outlet $1 . F+$ Outlet $2 . F$

Inlet $\cdot z[i]=$ Outlet $1 \cdot z[i]=$ Outlet $2 \cdot z[i]$

Inlet. $T=$ Outlet $1 . T=$ Outlet $2 . T$

\subsection{Heat Exchanger}

Since there is no mixture between the hot and cold streams in the heat exchanger both the global and component mass balances are trivial (eqs. 7 - 10). The heat exchanged between the streams is given by equations 11 and 12 , for the hot and cold sides, respectively. The heat exchanger area is calculated using the global heat transfer coefficient (eq. 13). An approximation for the logarithmic mean temperature difference described by $\mathrm{Chen}^{\mathrm{S1}}$ is used to facilitate the system convergence (eqs. $14-16)$.

InletHot.F $=$ OutletHot.F

InletCold.F $=$ OutletCold.$F$

InletHot. $z[i]=$ OutletHot. $z[i]$

InletCold. $z[i]=$ OutletCold. $z[i]$

$Q=C p_{H o t} \times$ InletHot.F $\times($ InletHot.T - OutletHot.T $)$

$Q=C p_{\text {Cold }} \times$ InletCold $. F \times($ OutletCold $. T-$ InletCold.$T)$ 


$$
\begin{aligned}
& Q=U \times A \times D T_{l m} \\
& D T_{l m}{ }^{0.3275}=D T_{1}{ }^{0.3275}+D T_{2}{ }^{0.3275} \\
& D T_{1}=\text { InletHot. } T-\text { OutletCold. } T \\
& D T_{2}=\text { OutletHot. } T-\text { InletCold. } T
\end{aligned}
$$

\subsection{Flash}

The flash model was used to simulate both the flash and the evaporator in the succinic acid production process. The model comprises an inlet stream, a vapor outlet and a liquid outlet. The global and component mass balances are shown in equations 17 and 18, respectively. The actual phase equilibrium was not calculated. Instead, all compounds with boiling points lower than the water were supposed to leave the equipment on the vapor stream along with part of the water. All other compounds leave the flash on the liquid stream (eq. 19). This is accomplished by specifying the variable $f$ between zero and one. Also, equation 20 specifies that the sum of mass fractions in the vapor and liquid streams are equal, which, together with equations 17 to 19 , guarantees that both sums are equal to one. The energy balance (eq. 21) is based on the heat capacity and latent heat of water, since the other compounds are present in low concentrations. Finally, thermal equilibrium is supposed (eq. 22).

Inlet. F $=$ OutletV.F + OutletL.F

Inlet. $F \times$ Inlet. $z[i]=$ OutletV. $F \times$ OutletV. $z[i]+$ OutletL. $F \times$ OutletL. $z[i](18)$ 
OutletV.F $\times$ OutletV. $z[i]=$ Inlet. $F \times$ Inlet. $z[i] \times f[i]$

$\sum_{i}$ OutletV.z[i] $=\sum_{i}$ OutletL. $z[i]$

Inlet. $F \times C p \times$ Inlet. $T+Q=$ OutletL. $F \times C p \times$ OutletL.T + OutletV.F $\times$

$(C p \times$ OutletV.T + VapHeat $)$

OutletV.T $=$ OutletL.T

\subsection{Fermenter}

The fermenter model comprises two inlets (substrate and air) and two outlets (succinic acid solution and fermentation gases). Besides the global mass balance (eq. 23), the component mass balance takes into account the consumed raw material and formed products based on the stoichiometric coefficients of the reactions and a conversion relative to the limiting reagent (eqs. 24 and 25). The reactions considered are:

$$
\mathrm{C}_{12} \mathrm{H}_{22} \mathrm{O}_{11}+1.5 \mathrm{O}_{2} \rightarrow 3 \mathrm{C}_{4} \mathrm{H}_{6} \mathrm{O}_{4}+2 \mathrm{H}_{2} \mathrm{O}
$$

$$
\mathrm{C}_{12} \mathrm{H}_{22} \mathrm{O}_{11}+9 \mathrm{O}_{2}
$$

$$
\begin{aligned}
& \rightarrow 0.081 \mathrm{C}_{3} \mathrm{H}_{4} \mathrm{O}_{3}+0.081 \mathrm{C}_{2} \mathrm{H}_{4} \mathrm{O}_{2}+0.405 \mathrm{C}_{2} \mathrm{H}_{6} \mathrm{O}+0.405 \mathrm{C}_{3} \mathrm{H}_{8} \mathrm{O}_{3} \\
& +9.57 \mathrm{CO}_{2}+7.84 \mathrm{H}_{2} \mathrm{O}
\end{aligned}
$$

Inlet. $F+$ Air. $F=$ Outlet. $F+$ Gases. $F$

Inlet. $F \times$ Inlet. $z[i]+$ Air. $F \times$ Air. $z[i]+\sum_{j}(r[j] \times \operatorname{stoic}[j, i]) \times M[i]=$ Gases. $F \times$ Gases.z[i] 
$r[j] \times M[l[j]]=($ Inlet. $F \times$ Inlet. $z[l[j]]+$ Air. $F \times$ Air. $z[l[j]] \times$ conv

To calculate the total volume necessary to carry the fermentation (eq. 26), the total batch time must be obtained from the duration of the four steps: filling, reaction, emptying and cleaning (eq. 27).

$V_{\text {total }} \times$ workingVolume $\times \rho \times$ ReactorUsage $=$ Inlet. $F \times T_{\text {total }}$

$T_{\text {total }}=T_{\text {filling }}+T_{\text {emptying }}+T_{\text {cleaning }}+T_{\text {reaction }}$

The mass of cells that needs to be re-grown each week should be calculated based on the number of reactors that are full or emptying at a giving time. Nevertheless, as explained in section 2, the methodology does not allow the models to have discontinuous functions. Therefore, a continuous approximation of the function was used (eq. 28).

$M_{\text {cells }}=\frac{\left(T_{\text {filling }}+T_{\text {reaction }}\right)}{T_{\text {total }}} \times V_{\text {total }} \times$ workingVolume $\times C_{\text {cells }}$

The productivity of the yeast (a specific productivity, mass of succinic acid/mass of cells/h) was calculated considering the amount of sucrose that is converted to succinic acid (eq. 29). Also, the power consumption for the reactor mixing is also calculated taking the reactors total volume (eq. 30).

$\operatorname{Pr} \times C_{\text {cells }} \times T_{\text {reaction }}=$ Inlet. $z[1] \times \operatorname{conv}[1] \times \operatorname{stoic}[1,3] \times \frac{M[3]}{M[1]} \times \rho_{\text {reactor }}$

$P_{\text {mix }} \times T_{\text {total }}=V_{\text {total }} \times P_{\text {specMix }} \times T_{\text {reaction }}$

The maximum volume of the reactor $\left(400 \mathrm{~m}^{3}\right)$ was used to calculate the reactor diameter (using an aspect ratio of 3, eq. 31), the mass of steel in each reactor (eq. 32) and 
consequently the steam required to heat the reactor to the sterilization temperature $\left(121^{\circ} \mathrm{C}\right)$ and the water to cool it back to the fermentation temperature (eqs. $33-35$ ).

$$
\begin{aligned}
& V_{\text {max }}=\frac{3 \times \pi \times D_{\text {reactor }}^{3}}{4} \\
& M_{\text {steel }}=\frac{21}{4} \times \pi \times D_{\text {reactor }}^{2} \times \text { Thickness } \times \rho_{\text {steel }} \\
& Q_{\text {ster }} \times T_{\text {total }}=C p_{\text {steel }} \times\left(T_{\text {steam }}-\text { Inlet.T }\right) \times M_{\text {steel }} \times \frac{V_{\text {total }}}{V_{\text {max }}} \\
& F_{\text {steam }} \times L_{\text {steam }}=Q_{\text {ster }} \\
& F_{\text {water }} \times C p_{\text {water }} \times \Delta T=Q_{\text {ster }}
\end{aligned}
$$

\subsection{Crystallizer}

In the crystallizer, besides the usual global and component mass balances (eqs. 36 and 37), the initial and final crystal volumes (eqs. 38 and 39) are used to calculated the crystal growth and residence time, using a specified overall crystal growth rate (eq. 40). Therefore, the crystallizer volume is calculated taking into account the space-time, the average density (eq. 41) and the working volume (85\%, eq. 42). Finally, thermal equilibrium is assumed (eq. 43).

Inlet. $F=$ OutletS.F + OutletL.F

Inlet. $F \times$ Inlet. $z[i]=$ OutletL. $F \times$ OutletL. $z[i]+$ OutletS. $F \times$ OutletS. $z[i](37)$

$V_{i}=\frac{4 \times \pi \times r_{i}^{3}}{3}$ 
$V_{f}=\frac{4 \times \pi \times r_{f}^{3}}{3}$

$\tau=\frac{r_{\text {average }} \times \rho_{\text {crystal }}}{4 \times R g}$

$\frac{1}{\rho_{L}}=\frac{\operatorname{Inlet} . z(S A)}{\rho_{\text {crystal }}}+\frac{1-\operatorname{Inlet} . \mathrm{z}(S A)}{1000 \mathrm{~kg} / \mathrm{m}^{3}}$

$V_{\text {reactor }}=\frac{\text { Inlet.F } \times \tau}{\rho_{L} \times 0.85}$

OutletL.T $=$ OutletS.T

\subsection{Dryer}

The amount of evaporated water, the inlet and outlet air streams were not represented by the basic stream defined here. They were represented as mass flows only, since there was no need for knowing their composition. The global mass balance is simplified, since it is supposed that no air is absorbed by the drying solid (eq. 44). Also, all water is evaporated (eq. 45). The amount of air needed in the dryer is calculated by two limiting factors, the equilibrium humidity at the outlet temperature (eq. 46) and the minimum heat transferred to the solid to evaporate all the water (eq. 47). The maximum value between these two is considered to be the real air flow (eq. 48), with the real outlet temperature and humidity of the air being calculated by equations 49 and 50 . Numbers in equations 47 and 50 are the heat capacity constants for the air. Finally, the dryer area is obtained by the amount of water evaporated and a specified mean evaporation rate ( $r_{e}$, eq. 51).

Inlet. $F=$ Outlet. $F+F_{\text {evap }}$ 


$$
\begin{aligned}
& F_{\text {evap }}=\text { Inlet. } F \times \text { Inlet. } z[\text { water }] \\
& F_{\text {air }}^{\prime} \times\left(H_{\text {out }}-\text { InletAir. } H\right)=F_{\text {evap }} \\
& F_{\text {air }}^{\prime \prime} \times\left(0.96 \times\left(\text { InletAir. } T-T_{\text {out }}\right)+\frac{7.5 \times\left(\text { Inlet } A \text { ir } . T^{2}-T_{\text {out }}^{2}\right)}{100000}\right)=F_{\text {evap }} * L_{\text {evap }}
\end{aligned}
$$

OutletAir. $F=\max \left(F_{\text {air }}^{\prime}, F_{\text {air }}^{\prime \prime}\right)$

OutletAir. $F \times($ OutletAir. $H-$ InletAir. $H)=F_{\text {evap }}$

OutletAir. F $\times\left(0.96 \times(\right.$ InletAir. $T-$ OutletAir. $\left.T)+\frac{7.5 \times\left(\text { InletAir. } T^{2}-\text { OutletAir. }^{2}\right)}{100000}\right)=$ $F_{\text {evap }} \times L_{\text {evap }}$

$A \times r_{e}=F_{\text {evap }}$

\section{Economic Analysis}

In order to perform the economic analysis of the process, both capital expenditures (CapEx) and operating expenditures (OpEx) were calculated. CapEx direct costs were based on the equipment purchase cost (EPC, eq. 52) and the equipment installed cost (EIC, eq. 53), with all other direct costs being based on these two, as show in Table S1. Equipment costing uses the scaling factor $(S F)$ considering the equipment sizing factor $\left(S_{\text {actual }}\right)$, a base size $\left(S_{\text {base }}\right)$, price $\left(\$_{\text {base }}\right)$ and an installation factor $(I F)$.

$E P C=\sum\left(\frac{S_{\text {actual }}}{S_{\text {base }}}\right)^{S F} \times \$_{\text {base }}$ 
$E I C=\sum I F \times\left(\frac{S_{\text {final }}}{S_{\text {base }}}\right)^{S F} \times \$_{\text {base }}$

Table S1: Direct and Indirect costs of CapEx.

\begin{tabular}{|l|l|}
\hline Direct costs & Value \\
\hline Piping & $31 \%$ of EPC \\
\hline Instrumentation and control & $18 \%$ of EPC \\
\hline Electrical equipment and materials & $10 \%$ of EPC \\
\hline Buildings & $38 \%$ of EPC \\
\hline Service facilities & $40 \%$ of EPC \\
\hline Yard improvement & $10 \%$ of EPC \\
\hline Land & $6 \%$ of EPC \\
\hline Indirect costs (IC) & \\
\hline Engineering and supervision & $8 \%$ of TDC \\
\hline Construction expenses & $10 \%$ of TDC \\
\hline Contractors fee & $5 \%$ of TDC \\
\hline Contingency & $8 \%$ of TDC \\
\hline
\end{tabular}

Therefore, the total direct costs (TDC) can be calculated from this two values (eq. 54), while the indirect costs (IC) were based on the TDC (Table S1, eq. 55).

$T D C=I E C+1.53 \times E P C$

$I C=0.31 \times T D C$

The fixed capital investment $(F C I)$ is the sum of the direct and indirect costs of CapEx (eq. 56). Also, the working capital (WC) is based on the indirect costs, being fixed at $10 \%$ of the IC (eq. 57). Finally, the total capital investment (TCI) is the sum of $F C I$ and $W C$ (eq. 58).

$F C I=T D C+I C$

$W C=0.1 \times I C$

$T C I=F C I+W C$ 
The plant OpEx was calculated considering fixed costs, direct costs, raw materials and utilities costs. The raw materials $(R M)$ comprise sucrose, sodium hydroxide, water, ammonia and zeolite. Total RM costs were calculated (eq. 59) from the mass flow $\left(F_{i}\right)$ and price per mass unit $\left(\$_{i}\right)$ for each raw material $i$ for one operating time (OT, considered equal to 330 days). The raw materials and utilities costs were kept equal to the original study (Efe, van der Wielen and Straathof, 2013, Table S2). The utilities costs $(U)$ were calculated from the electric energy $(E E)$, cooling water $(C W)$ and natural gas $(N G)$ consumptions (eq. 60). The EE was calculated from the main pieces of equipment consumption and increased in $50 \%$ to account for the auxiliary equipments.

$R M=O T \times\left(\$_{S u c} \times F_{S u c}+\$_{N a O H} \times F_{N a O H}+\$_{W} \times F_{W}+\$_{A m} \times F_{A m}+\$_{Z} \times F_{Z}\right)(59)$

$U=O T \times\left(\$_{E E} \times E E \times 1.5+\$_{C W} \times C W+\$_{N G} \times N G\right)$

Table S2: Raw material and utilities price per unit.

\begin{tabular}{|l|l|}
\hline Item & Price \\
\hline Sucrose & $212 \mathrm{US} \$ /$ tonne \\
\hline $\mathrm{NaOH}$ & $200 \mathrm{US} \$ /$ tonne \\
\hline Process water & $0.27 \mathrm{US} / \mathrm{m}^{3}$ \\
\hline Ammonia & $310 \mathrm{US} \$ /$ tonne \\
\hline Zeolite & $33000 \mathrm{US} \$ /$ tonne \\
\hline Electric energy & $0.07 \mathrm{US} \$ / \mathrm{MWh}$ \\
\hline Cooling water & $0.014 \mathrm{US} \$ \mathrm{~m}^{3}$ \\
\hline Natural gas & $4.1 \mathrm{US} \$ / \mathrm{GJ}$ \\
\hline
\end{tabular}

OpEx direct costs $(O D C)$ comprise operating labor (OperLabor), supervision (superv), laboratory charges (LabChar), maintenance and repair (Maint) and operating supplies (OperSupplies) - eq. 61. The Operating labor was considered constant as a simplification of the process and both supervision and laboratory charges were based on its value (both $15 \%$ 
of it). The maintenance cost was taken as $5 \%$ of the fixed capital investment and operating supplies $15 \%$ of maintenance cost.

$O D C=$ OperSupplies + LabChar + Maint + Superv + OperLabor

The OpEx fixed costs $(O F C)$ were based on the insurance (Insur), administrative costs (AdmCosts), distribution and marketing (Mark) and plant overhead (PlantOverhead) - eq. 62. The plant overhead was taken as $50 \%$ of the maintenance, operating labor and supervision costs. The administrative cost was considered to be $20 \%$ of operating labor, insurance as $3 \%$ of $F C I$ and marketing and distribution as $2 \%$ of total operating costs (OC, eq. 63).

OFC $=$ Insur + AdmCosts + PlantOverhead + Mark

$O C=O F C+O D C+R M+U$

For the cash flow $(C F)$ calculation, it was considered one year of design (when only the $I C$ was expend), two years of construction (with half of the TDC being expend each year) and ten years of operation (eqs. 64a-e). The only source of revenue was the selling of succinic acid (eq. 65).

$C F[1]=-I C$

$C F[2: 3]=\frac{-T D C}{2}$

$C F[4]=$ Revenue $-O C-\operatorname{Tax}[1]-W C$

$C F[5: 12]=$ Revenue $-O C-\operatorname{Tax}[2]$ 
$C F[13]=$ Revenue $-O C-\operatorname{Tax}[3]+W C$

Revenue $=\$_{S A} \times \dot{M}_{S A} \times O T$

The taxes were calculated based on equations 66a-c, with a linear depreciation over the 10 years of operation.

$\operatorname{Tax}[1]=($ Revenue - OC - Depreciat $-W C) \times 0.34$

$\operatorname{Tax}[2]=($ Revenue $-O C-$ Depreciat $) \times 0.34$

$\operatorname{Tax}[3]=($ Revenue - OC - Depreciat $+W C) \times 0.34$

Finally, the discounted cash flow $(D C F)$ is calculated (eq. 67) which is used to calculate the $N P V$ of the process (eq. 68)

$D C F=\frac{C F}{(1+r)^{i}}$

$N P V=\sum_{i=0}^{12} D C F[i+1]$

\section{Breakdown of the investment and operating costs}

Table S3 and Figure S1 show the breakdown of the investment and operating costs for the base case, respectively. 
Table S3: Breakdown of the investment costs for the base case.

\begin{tabular}{|l|l|l|}
\hline Sector & Installed equipment cost $\left(\mathrm{US} \$ \times 10^{3}\right)$ & Percentage \\
\hline Sterilization & 5277.3 & $10.1 \%$ \\
\hline Fermentation & 43005.5 & $82.3 \%$ \\
\hline Separation & 380.5 & $0.7 \%$ \\
\hline Concentration & 582.4 & $1.1 \%$ \\
\hline Crystallization & 1216.8 & $2.3 \%$ \\
\hline Utilities & 1804.8 & $3.5 \%$ \\
\hline Total & 52267.4 & \\
\hline
\end{tabular}

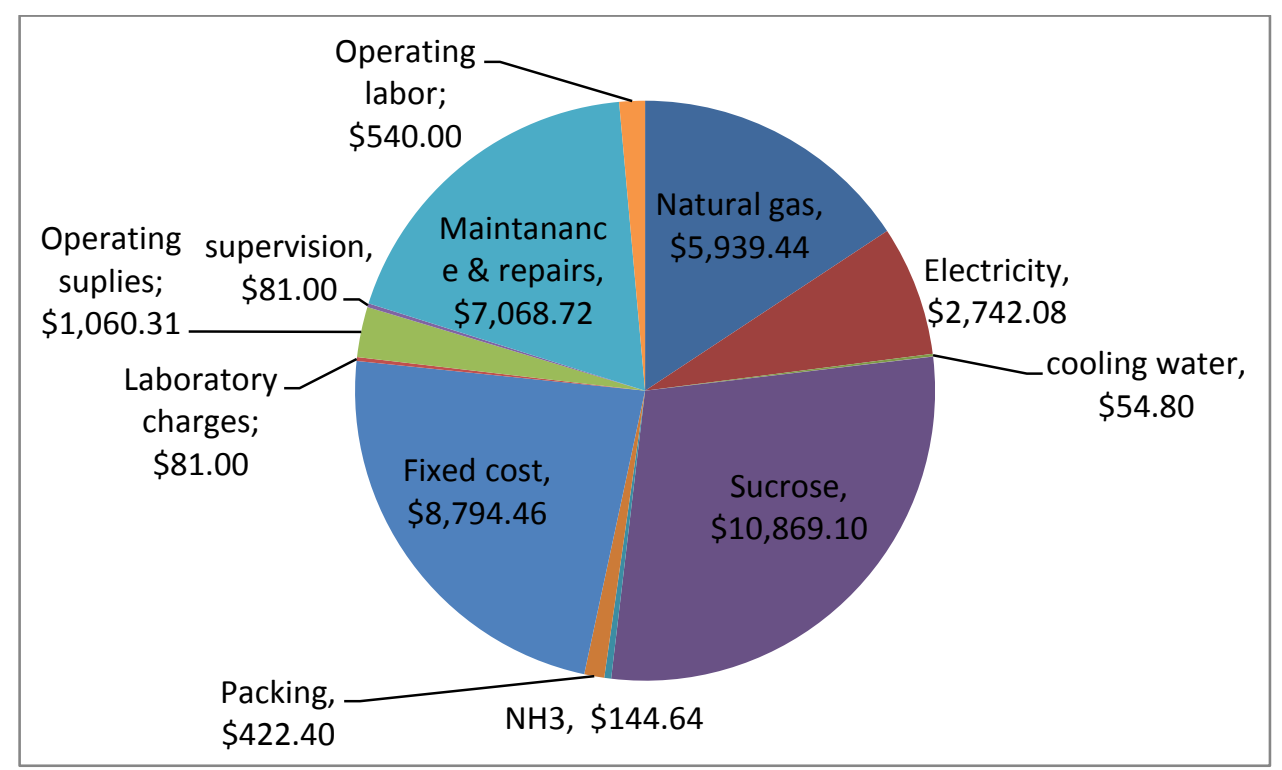

Figure S1: Breakdown of the operating costs for the base case. The prices shown are in US $\$ \times 10^{3}$.

\section{References}

(S1) Chen, J. J. J. Comments on improvements on a replacement for the logarithmic mean. Chem. Eng. Sci. 1987, 42, 2488. 